\title{
Kernos
}

Revue internationale et pluridisciplinaire de religion grecque antique

$10 \mid 1997$

Varia

\section{J. FISCHER, Griechisch-römische Terrakotten aus}

\section{Ägypten}

\section{Michel Malaise}

\section{OpenEdition}

Journals

Édition électronique

URL : http://journals.openedition.org/kernos/695

DOI : $10.4000 /$ kernos.695

ISSN : 2034-7871

\section{Éditeur}

Centre international d'étude de la religion grecque antique

\section{Édition imprimée}

Date de publication : 1 janvier 1997

Pagination : $364-367$

ISSN : 0776-3824

\section{Référence électronique}

Michel Malaise, "J. FISCHER, Griechisch-römische Terrakotten aus Ägypten », Kernos [En ligne], 10 |

1997, mis en ligne le 12 avril 2011, consulté le 24 septembre 2020. URL : http://

journals.openedition.org/kernos/695 ; DOI : https://doi.org/10.4000/kernos.695 
sections (le culte : divinités; le culte : héros; le culte : autres témoignages; le patrimoine mythico-religieux; la ktisis; la religion de la pólis en dehors de son territoire; les témoignages à caractère littéraire). En général, chaque inscription est accompagnée d'un lemme descriptif. Pour les textes littéraires, le contexte est parfois précisé, le texte grec ou latin est fourni, avec un apparat critique ne signalant que les variantes en rapport avec les noms des divinités ou des héros; une traduction est proposée, et, suivant les cas, un commentaire plus ou moins détaillé sur les principaux problèmes posés par le texte; on trouve enfin une bibliographie. L'intérêt de ce genre d'entreprise est patent, l'absence de recueils de sources rendant parfois fort difficile, voire impossible, le travail sur des dossiers où le matériel inédit ou d'accès difficile, en raison notamment du caractère local des publications, est abondant. De même, on apprécie grandement le souci des A. d'accompagner les documents d'un commentaire, lorsque cela leur paraît utile, dans l'intention de procéder à une première exégèse de ceux-ci. Il convient toutefois de ne pas perdre de vue qu'il s'agit alors déjà d'une interprétation historique qui, comme telle, portera nécessairement le poids des idées, des a priori de ceux qui les écrivent. L'ensemble est suivi d'une bibliographie, de différents index, d'un renvoi aux principales éditions de textes et, pour terminer, des planches photographiques.

Véronique KRINGS (Université de Liège)

Jutta Fischer, Griechisch-römische Terrakotten aus Ägypten. Die
Sammlungen Sieglin und Schreiber. Dresden, Leipzig, Stuttgart, Tübingen, Tübingen, Wasmuth, 1994. 1 vol. in $-4^{\circ}, 470$ p., 131 pl. (Tübinger Studien zur Archäologie und Kunstgeschichte, 14). Prix : 372 D.M.

La présente étude est consacrée aux très riches collections de terres cuites grécoromaines d'Égypte, rassemblées à la fin du siècle dernier et au début de ce siècle, par E. vON ZiEglin et Th. SCHREIBER, au départ de fouilles effectuées à Alexandric ou d'achats opérés dans la même ville, et dont une partie avait été publiée en 1924 par J. VOGT. Cet important corpus, riche de 1269 pièces, dispersées dans plusieurs villes d'Allemagne, est aujourd'hui l'objet d'une publication soignée, et magnifiquement illustrée, qui constitue une contribution essentielle à l'étude des productions sorties des ateliers des coroplathes depuis l'époque pré-ptolémaïque jusqu'au cœur de l'Égypte romaine. Ces terres cuites bénéficient depuis quelques années d'un regain d'intérêt, comme le prouve la publication de catalogues récents, dont G. NACHTERGAEL a rendu compte dans une chronique fondamentale (Terres cuites de l'Égypte grécoromaine. Á propos de quatre Catalogues récents, in CdE, 70 [1995], p. 254-294) pour l'étude et la compréhension de ces objets. Un dernier ouvrage consacré par L. TöröK aux terres cuites de Budapest, et que nous présentons dans le même numéro de cette revue, nous donne à espérer que ce mouvement ne s'arrêtera pas en si bon chemin.

L'ouvrage de Jutta FISCHER ne nous offre pas seulement un catalogue soigné de 357 pages, mais il commence par nous fournir une longue étude introductive (p. 1-105) mettant l'accent sur le développement typologique et chronologique des terres cuites.

Après avoir rappelé l'histoire de la collection (ch. I), l'A. se penche dans un ch. II sur les problèmes techniques (terre, technique et ateliers) qui permettent de distinguer trois types : les œuvres pré-ptolémaïques sorties des ateliers de Memphis, les figurines de haute époque hellénistique et les terres cuites dites du Fayoum, surtout d'époque 
impériale. Ce dernier terme, souvent utilisé, est toutefois imprécis car il ne se laisse pas clairement délimiter, ni d'un point de vue géographique, ni d'un point de vue chronologique. À l'exception des terres cuites pré-hellénistiques, les figures sont tirées de moules bivalves en gypse. Après moulage, elles sont retouchées, puis peintes. Il est malheureusement difficile d'identifier les ateliers, faute d'indices assurés et à cause des variantes de détails que peuvent présenter des productions issues d'une même officine.

Avec le chapitre III, le lecteur aborde l'examen de la coroplastique pré-ptolémaïque, limitée à quelques types, surtout des figures phalliques, exécutées depuis la fin du $\mathrm{VI}^{\mathrm{e}}$ siècle, essentiellement à Memphis. L'A. décèle dans cette production une influence du culte dionysiaque véhiculé par les Grecs établis dans cette cité et considère que ces images ont dû servir comme ex-voto dans le culte funéraire, fondé essentiellement sur des rites de fécondité. Avec l'époque hellénistique, les figurines phalliques s'apparentent davantage au monde des vivants et particulièrement à celui des desservants du culte, en liaison étroite avec Harpocrate. Le chapitre IV s'attache aux types grecs qui se développent à partir de la fondation d'Alexandrie: femmes vêtues d'un manteau (dites Tanagra) et garçons caractérisés comme macédoniens par le port de la kausia.

Les caricatures et grotesques, étudiés dans le ch. V, voient le jour avant le milieu du III $^{\mathrm{e}}$ siècle et s'épanouissent dans le dernier quart du III $^{\mathrm{e}}$ siècle et au début du II $^{\mathrm{e}}$ siècle. $\mathrm{Au} \mathrm{III}^{\mathrm{e}}$ siècle appartiennent nègres au crâne rasé, êtres difformes et vieilles femmes. Avec le $\mathrm{II}^{\mathrm{e}}$ siècle apparaissent de nouvelles créations : serviteurs du culte, musiciens, danseurs et prêtres, patèques portant un enfant sur l'épaule. Ces types laissent la place avec l'époque romaine à des figurines plus grossières, peu modelées, pourvues d'attributs divers, mais les véritables nouvelles créations, comme celle des gladiateurs, sont rares. Cette production grotesque est souvent à mettre en rapport avec le domaine religieux et cultuel, ainsi que le révèlent des images de nains, au long phallus et porteurs d'un vase, qui doivent appartenir à l'entourage d'Harpocrate, ou de nains danseurs et musiciens que leurs attributs désignent comme des participants à une fête religieuse. Peut-être est-ce l'incapacité à travailler de ces êtres difformes qui les amena à trouver leur mode de subsistance en se mettant au service des festivités de la classe aisée. Telle pourrait être, selon l'A., l'origine de la vogue des grotesques.

Le chapitre VI qui nous introduit dans le monde des dieux aborde une documentation capitale pour la compréhension de la religiosité privée dans l'Égypte grécoromaine. On constate à nouveau que la divinité la plus populaire est Harpocrate; puis viennent Isis et les figurines féminines à mettre en rapport avec son culte. Relativement nombreuses sont également les statuettes de Bès, de Sarapis et d'Osiris-Canope, tout comme les représentations de femmes nues, bras collés au corps ou portant une corbeille sur la tête, qui semblent à mettre en rapport avec le culte d'Hathor-Aphrodite. Ces divinités égyptiennes revêtent toujours une apparence hellénisée, ce qui montre qu'elles sont produites pour une clientèle grecque, ou du moins hellénisée, sans doute assez modeste vu l'humble matériau de la terre cuite. Il est important de noter que les représentations fidèles à l'iconographie proprement égyptienne sont, elles produites, en faïence ou en bronze. Pour sa part, la présence des divinités grecques (Athéna, Déméter, Dionysos, Éros et Aphrodite) est beaucoup plus discrète, ce qui nous semble témoigner de la perte d'intérêt des Grecs d'Égypte pour leur propre panthéon.

L'évolution chronologique permet de se faire une idée de la vogue des divinités en fonction de l'époque. Durant le $\mathrm{III}^{\mathrm{e}}$ siècle et la première moitié du $\mathrm{II}^{\mathrm{e}}$ siècle, on ren- 
contre des statuettes de Bès, mais surtout d'Harpocrate; l'image d'Harpocrate au pot voit le jour après le milieu du III $^{\mathrm{e}}$ siècle et connaîtra une vogue qui ne se tarira pas durant l'époque impériale. C'est aussi au III $^{\mathrm{e}}$ siècle que naît le type d'Harpocrate debout tenant une corne d'abondance. Relativement fréquente également durant la haute époque hellénistique est l'image de l'Aphrodite anasyroméné, relevant son vêtement pour découvrir son sexe. Les pseudo-Baubo, femmes nues assises sur le sol, cuisses écartées et montrant leur sexe, sont connues au moins depuis le milieu du $\mathrm{II}^{\mathrm{e}}$ siècle avant notre ère et subsistent jusqu'au milieu du $\mathrm{III}^{\mathrm{e}}$ siècle ap. J.-C. On notera pour cette haute époque hellénistique l'absence d'Isis et de Sarapis, mais aussi de Dionysos et des Dioscures, dont les cultes sont cependant bien attestés par ailleurs à Alexandrie. La plupart des divinités égyptiennes représentées symbolisent des aspects de la fécondité et reflètent clairement des croyances populaires.

La période qui s'étend du milieu du $\mathrm{II}^{\mathrm{e}}$ siècle au début de l'époque impériale voit se poursuivre la fabrication d'images anciennes, mais naissent avec la période hellénistique tardive des terres cuites d'Aphrodite et de Déméter, ainsi que l'image d'IsisBoubastis assise dans une corbeille. Le type d'Isis debout, tenant sistre et situle, est peu fréquent et semble limité dans la coroplastique au $\mathrm{I}^{\text {er }}$ siècle av. $\mathrm{J}$.-C. et au $\mathrm{I}^{\text {er }}$ siècle ap. J.-C. La documentation relative à ce type connu par ailleurs nous donnerait même à penser que cette présentation pourrait ne pas être antérieure à l'époque romaine. Une nouveauté caractéristique de cette période est la multiplication des attributs. Il est intéressant de noter que la plus ancienne représentation d'Isis est celle d'Isis-Boubastis, donnée recoupée par d'autres informations. Nous avons en effet constaté que l'aspect maternel d'Isis a séduit très tôt les Grecs, comme le révèlent des statuettes d'Isis lactans de la fin de l'époque pharaonique porteuses d'une dédicace en grec ( $c f$. MASSON, $R d E$, 29 [1977], p. 57-61; G. WaGner, Hommages à J. Leclant, III, p. 485-489). En outre, toutes les dédicaces gravées en Égypte en l'honneur de Boubastis sont le fait de Grecs, qui n'hésitent pas à représenter la déesse sous sa forme égyptienne de chatte, ainsi que le montre le texte inscrit sur la plinthe du socle d'une chatte du IV ${ }^{\mathrm{e}}$ ou début du III siècle provenant de Boubastis ( $c f$. G. WAGNER, ASAE, 69 [1983], p. 247-252).

Le début de l'époque impériale a apporté peu de nouveaux types, mis à part quelques exceptions comme Harpocrate à cheval ou l'introduction d'Athéna, identifiée à la déesse égyptienne Neith. Cette pause est mise en relation par l'A. avec l'attitude plus que réticente d'Auguste à l'endroit des dieux égyptiens. On peut toutefois se demander en quoi les goûts d'Auguste ont pu jouer un rôle en terre égyptienne sur les besoins religieux de classes apparemment modestes.

Durant la seconde moitié du $\mathrm{I}^{\mathrm{er}}$ siècle et la première moitié du $\mathrm{II}^{\mathrm{e}}$ siècle, la production des types remontant à l'époque hellénistique se poursuit, mais, avec la fin du $\mathrm{I}^{\mathrm{er}}$ siècle, naissent deux nouvelles versions d'Harpocrate présentant le jeune dieu touillant dans son pot ou portant sur l'épaule une image d'Harpocrate-Min. Autre enrichissement advenu au cours du $1^{\text {er }}$ siècle est la création en séries de statuettes d'Isis, notamment d'Isis nourrissant Harpocrate et d'Isis-Thermouthis, de Sérapis trônant, d'OsirisCanope, et vraisemblablement d'Hermanubis. Le répertoire s'enrichit donc de nombreuses figurations de divinités égyptiennes et la coroplastique ne reflète plus seulement les croyances populaires fondées sur la fécondité. C'est aussi l'époque où les insignes isiaques passent sur les images d'Aphrodite et de la pseudo-Baubo.

Après le milieu du II $^{\mathrm{e}}$ siècle, la coroplastique connaît sa période d'apogée et pratiquement tout le répertoire créé depuis l'époque hellénistique se maintient. Fin du $\mathrm{II}^{\mathrm{e}}$ 
siècle apparaissent des statuettes d'orants et d'orantes, bras étendus. À l'époque des Sévères, l'iconographie des dieux et des humains commence à se mélanger de sorte qu'Aphrodite, et même Isis, peuvent être coiffées à la mode. Caractéristique aussi est l'importance quantitative des terres cuites figurant des desservants du culte : femmes à la corbeille, danseuses à la torche, orants et orantes, prêtresses d'Isis. Encore abondante au début du $\mathrm{III}^{\mathrm{e}}$ siècle, la production des terres cuites commence à régresser avec la deuxième moitié de ce siècle.

Les terres cuites répertoriées dans le catalogue font, chacune, l'objet d'une notice très précise, avec données matérielles, description, date et bibliographie fournissant de nombreux parallèles. L'ordre de présentation est le suivant. Après les figurines d'époque pré-hellénistiques $\left(n^{\circ} 1-31\right)$, surtout phalliques, viennent les types qui reprennent des modèles grecs et produits à la fin du $I V^{\mathrm{e}}$ siècle $\left(\mathrm{n}^{\circ} 32-318\right.$ : figures et têtes féminines, garçons et têtes de garçons). La section suivante est réservée aux acteurs et aux masques ( $n^{\circ} 319-358$ ) qui s'enracinent aussi surtout dans la tradition grecque. Viennent ensuite caricatures et grotesques ( $n^{\circ} 350-530$ ), dont la floraison s'étend de la fin du $\mathrm{III}^{\mathrm{e}}$ siècle au $\mathrm{I}^{\mathrm{er}}$ siècle av. J.-C. et qui reflètent le mariage de thèmes alexandrins avec le style grec. Le monde des dieux constitue le plus grand groupe ( $\mathrm{n}^{\circ}$ 531-953); commençant timidement avec le début de l'hellénisme, les figurines divines se multiplient pour s'épanouir avec l'époque romaine. Ensuite sont publiées des figurines de genre, danseuses, orants et orantes, cavaliers, guerriers ( $n^{\circ}$ 954-1060) et quelques varia ( $\left.n^{\circ} 1061-1085\right)$. Le catalogue se poursuit par les représentations animales ( $n^{\circ}$ 1086-1163), surtout d'époque romaine, et enfin se clôture avec les lampes, objets et vases plastiques ( $\left.n^{\circ} 1164-1257\right)$ et quelques faux $\left(n^{\circ} 1258-1269\right)$.

Tous les chercheurs intéressés par l'Égypte gréco-romaine sauront gré à l'A. d'avoir mis à leur disposition une documentation aussi riche et d'avoir fourni un réel effort de datation, entreprise toujours difficile. Certes, faute de données précises sur l'origine des objets publiés, les recherches exposées reposent essentiellement sur des considérations stylistiques, mais leur exactitude est contrôlée par des trouvailles effectuées in situ, par exemple à Tell Atrib et à Karanis. Volontairement, l'A. n'a abordé les questions d'histoire religieuse que de façon indirecte et sommaire à travers les notices du catalogue, tout comme elle a laissé de côté les questions posées par l'utilisation de ces objets. Même si le lecteur trouvera sans peine dans d'autres recueils des renseignements sur la portée religieuse des figurines, on peut regretter cette décision qui conduit J.F. à parler de « déesse nue », appellation vague, et de «Baubo », dénomination erronée. Il n'en demeure pas moins vrai que la présente publication deviendra une référence obligée pour les études ultérieures consacrées aux terres cuites de l'Égypte gréco-romaine. Puisse venir un jour où l'accumulation de données archéologiques permettra d'établir un corpus dont les attributions chronologiques reposeront sur des considérations stratigraphiques! 